\title{
Information particle
}

\author{
Minh-Hoang Nguyen \\ Tam-Tri Le \\ Centre for Interdisciplinary Social Research \\ Phenikaa University \\ Yen Nghia, Ha Dong, Hanoi 100803, Vietnam
}

December 11, 2021

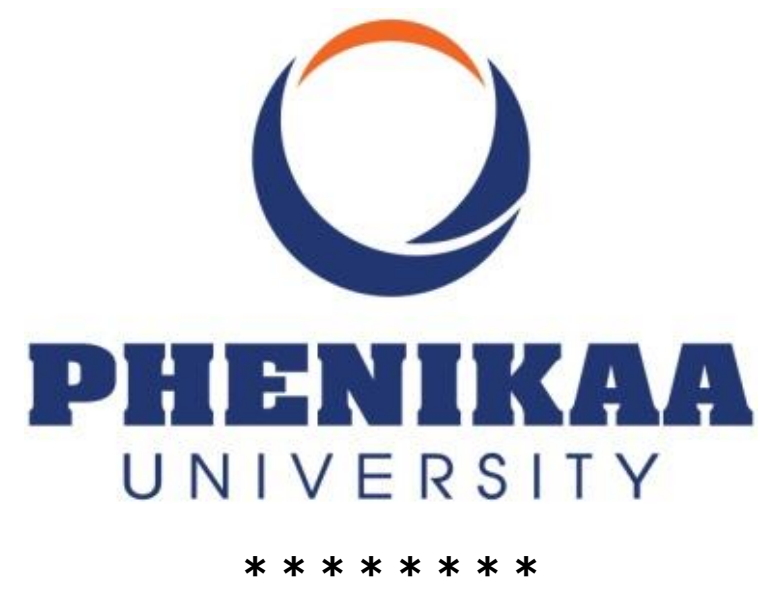

For a very long time, we have been wondering what is real, what is not, and how we can distinguish between reality and non-reality subjectively. To answer these questions, the first step is to have a medium that not only demonstrates the features of reality and nonreality but also helps us measure and compare reality and non-reality. Therefore, we propose an approach of treating information as an intermediate (or medium). The intermediate can be thought of as an information particle. That particle has the following three properties:

- It is a frame that sets the boundary for a concept.

- It requires at least one value to exist, but it can hold multiple values simultaneously.

- During the transmission (e.g., communication, sensory perceptions) process, it is an inducted representative (of the corresponding concept) with a singular value. When being processed within the mind, it is deducted into a collection of values based on the individual's mindsponge mechanism [1,2].

This requires further theoretical development and empirical validation.

\section{References}


1. Vuong QH. (2016). Global mindset as the integration of emerging socio-cultural values through mindsponge processes: A transition economy perspective. In J. Kuada (Ed.), Global Mindsets: Exploration and Perspectives (pp. 123-140). New York: Routledge.

2. Vuong QH, Napier NK. (2015). Acculturation and global mindsponge: An emerging market perspective. International Journal of Intercultural Relations, 49, 354-367. 